\title{
HUBUNGAN DUKUNGAN PETUGAS KESEHATAN DENGAN PERILAKU WUS (WANITA USIA SUBUR) DALAM PEMERIKSAAN IVA
}

\author{
"Shufia Aulia Citra', Ismarwati²

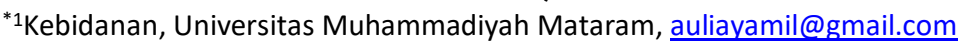 \\ ${ }^{2}$ Kebidanan, Universitas 'Aisyiyah Yogyakarta
}

\section{INFO ARTIKEL}

Riwayat Artikel:

Diterima: 20-01-2019

Disetujui: 22-07-2019

\section{Kata Kunci:}

Dukungan Petugas

Keseatan

Perilaku WUS

Pemeriksaan IVA

\section{A. LATAR BELAKANG}

Kanker serviks adalah kanker paling sering keempat pada wanita dengan perkiraan 570.00o kasus baru pada tahun 2018 dan mewakili 6,6\% dari semua kanker pada wanita. Sekitar 90\% kematian akibat kanker serviks terjadi di negara-negara berpenghasilan rendah dan menengah (WHO, 2018). Survei yang dilakukan WHO menunjukkan setiap tahunnya terjadi 300.000 kematian yang disebabkan oleh kanker serviks (Sartika, 2018). Menurut data Globocon tahun 2018, kasus baru kanker serviks di Indonesia mencapai 32.469 jiwa (Putri, 2019). Merujuk pada data yang dipaparkan Kementerian Kesehatan per 31 Januari 2019, angka kanker serviks sebesar 23,4 per 100.000 penduduk dengan rata-rata kematian 13,9 per 100.00o penduduk (Abdi, 2019).

Berdasarkan provinsi di Indonesia, prevalensi kanker tertinggi adalah Daerah Istimewa Yogyakarta sebesar 9,66\% dan terendah adalah Maluku Utara 1.95\% (Kemenkes RI, 2015). Data dari Dinas Kesehatan Provinsi DIY menyebutkan angka kejadian kanker serviks pada tahun 2012 sejumlah 1.879 orang, 63,07\% rawat inap dan $36,93 \%$ menjalani rawat jalan. Sedangkan pada tahun 2013 terdapat 1.459 kasus, 70,45\% menjalani rawat inap dan 29,75\% menajalani rawat jalan (Dinas Kesehatan DIY, 2014).

Skrining kanker serviks secara teratur dapat mengurangi angka kematian akibat kanker serviks stadium lanjut. Kanker serviks yang ditemukan pada stadium dini memberikan harapan hidup sebesar 92\% (Krishan, 2013). Sebagian besar pasien datang dalam kondisi yang sudah parah dan sulit di sembuhkan. Pasien yang datang pada stadium IA dan IIA $(28,6 \%)$, stadium IIB - IVB $(66,4 \%)$ dan stadium IIIB (37,3\%) (Moerdijat et all 2008, cit Yuliwati 2012). Departemen Kesehatan bersama profesi terkait lainnya telah membuat program berupa penyelenggaraan pilot proyek deteksi dini kanker leher rahim dengan pemeriksaan IVA (Depkes, 2010). Hasil kegiatan tersebut, dari 2007 sampai 2014, yaitu telah dilakukan skrining terhadap 904.099 wanita $(2,45 \%)$, hasil IVA positif sebanyak 44.654 orang $(4,94 \%)$. Angka tersebut masih jauh untuk mencapai target yaitu deteksi dini terhadap 50\% perempuan usia 30-50 tahun selama 5 tahun (Wahidin, 2015).

Rendahnya cakupan IVA disebabkan oleh beberapa hal, merasa malu, takut, dan tidak merasa membutuhkan sehingga tidak melakukan pemeriksaan IVA. Petugas kesehatan sebagai pengayom masyarakat termasuk faktor yang dapat mempengaruhi perilaku wanita untuk melakukan pemeriksaan IVA. Wanita yang diingatkan oleh petugas kesehatan untuk melakukan pemeriksaan kesehatan cenderung memiliki keinginan yang kuat untuk melaksanakan pemeriksaan tersebut (Chigbu, et al., 2013).

Menurut teori Green, perilaku ditentukan oleh tiga faktor utama, salah satunya faktor Penguat (reinforcing factors). Faktor penguat berupa sikap dan prilaku 
kesehatan dari orang lain. Sikap dan perilaku petugas kesehatan disini adalah bagaimana para petugas kesehatan (perawat, dokter, bidan, dan tenaga kesehatan lainnya) memperlakukan pasien. Memberikan motivasi dan dukungan sangat diperlukan untuk meningkatkan keaktifan wanita dalam melakukan pemeriksaan ke puskesmas (Emilia, 2010).

Studi pendahuluan yang dilakukan di Dinas Kesehatan Kabupaten Bantul menunjukkan, terdapat 6635 wanita usia subur di Puskesmas Banguntapan I dan hanya 23 orang $(0,35 \%)$ yang telah melakukan pemeriksaan IVA. Berdasarkan hasil wawancara dengan Bidan di Puskesmas Banguntapan I, menyatakan bahwa telah melakukan upaya pengenalan IVA dengan cara menawarkan pemeriksaan IVA pada wanita yang melakukan pemasangan maupun kontrol alat kontrasepsi IUD.

\section{B. METODE PENELITIAN}

Jenis penelitian ini adalah kuantitatif korelasi dengan pengambilan data cross-sectional. Populasi dalam penelitian ini adalah seluruh WUS di Dusun Ngipik wilayah kerja Puskesmas Banguntapan I Bantul Yogyakarta yang berjumlah 157 orang. Pengambilan sampel dilakukan dengan menggunakan sistematic random sampling dan diperoleh 61 orang WUS. Kriteria inklusi dalam penelitian ini yaitu WUS usia 20-50 tahun yang telah menikah di wilayah kerja Puskesmas Banguntapan I Bantul Yogyakarta dan telah terpapar oleh petugas kesehatan.

Pada penelitian ini alat yang digunakan adalah kuisioner. Metode pengumpulan data menggunakan data primer. Analisa data dalam penelitian ini adalah dengan menggunakan distribusi frekuensi dan menggunakan uji statistik Chi Square untuk mengetahui adanya hubungan.

\section{HASIL DAN PEMBAHASAN}

\section{Hasil}

\section{a. Karakteristik Responden}

Responden dalam penelitian ini dalah Wanita Usia Subur usia 20-50 tahun yang telah menikah dan pernah terpapar oleh petugas kesehatan yang berjumlah 61 orang. Sebagian besar responden (59\%) atau sebanyak 36 responden berada dikisaran usia < 40 tahun dan sebagian kecil (41\%) atau sebanyak 6 responden dikisaran usia $\geq 40$ tahun.

Tingkat pendidikan responden sebagian besar responden $(54,1 \%)$ atau 33 responden memiliki tingkat pendidikan tinggi. Sebagian kecil responden $(45,9 \%)$ atau sejumlah 28 orang memiliki tingkat pendidikan rendah.

b. Analisis Univariat

TABEL 1

Distribusi Frekuensi Dukungan Petugas Kesehatan di Wilayah Kerja Puskesmas Banguntapan I Bantul

\begin{tabular}{cccc}
\hline No & Dukungan & Frekuensi & $\%$ \\
\hline
\end{tabular}

\begin{tabular}{lccc}
\hline 1. & Tinggi & 34 & 55,7 \\
2. & Sedang & 17 & 27,9 \\
3. & Rendah & 10 & 16,4 \\
& Total & 61 & 100 \\
\hline
\end{tabular}

Setelah dilakukan analisis tentang dukungan petugas kesehatan, dari 61 responden sebagian besar $(55,7 \%)$ atau 34 responden mendapatkan dukungan petugas kesehatan yang tinggi. Sedangkan sebanyak $(16,4 \%)$ atau 10 responden mendapat dukungan petugas kesehatan yang rendah.

TABEL 2

Distribusi Frekuensi Perilaku WUS dalam Pemeriksaan IVA di Wilayah Kerja Puskesmas Banguntapan I Bantul

\begin{tabular}{cccc}
\hline No & Perilaku WUS & Frekuensi & \% \\
\hline 1. & Periksa & 36 & 59 \\
2. & Tidak Periksa & 25 & 41 \\
& Total & 61 & 100,0 \\
\hline
\end{tabular}

Perilaku Wanita Usia Subur (WUS), dari 61 responden sebagian besar (59\%) atau 36 responden melakukan pemeriksaan IVA, sedangkan sebanyak (41\%) atau 25 orang tidak melakukan pemeriksaan IVA.

\section{c. Analisis Bivariat}

TABEL 3

Hubungan Dukungan Petugas Kesehatan dengan

Perilaku WUS dalam Pemeriksaan IVA di Wilayah Kerja Puskesmas Banguntapan I Bantul

\begin{tabular}{|c|c|c|c|c|c|c|c|}
\hline \multirow{3}{*}{$\begin{array}{l}\mathbf{N} \\
\mathbf{o}\end{array}$} & \multicolumn{7}{|c|}{ Perilaku WUS } \\
\hline & \multirow[t]{2}{*}{ Dukungan } & \multicolumn{2}{|c|}{ Periksa } & \multicolumn{2}{|c|}{$\begin{array}{c}\text { Tidak } \\
\text { Periksa }\end{array}$} & \multicolumn{2}{|c|}{ Total } \\
\hline & & $\mathbf{n}$ & $\%$ & $\mathbf{n}$ & $\%$ & $\mathbf{n}$ & $\%$ \\
\hline 1. & Tinggi & 22 & 64,7 & 12 & 35,3 & 34 & 100 \\
\hline 2. & Sedang & 12 & 70,6 & 5 & 29,4 & 17 & 100 \\
\hline \multirow[t]{3}{*}{3.} & Rendah & 2 & 20 & 8 & 80 & 10 & 100 \\
\hline & Total & 36 & 59 & 25 & 41 & 61 & 100 \\
\hline & \multicolumn{7}{|c|}{$p$ value $=0,021<\alpha=0,05$} \\
\hline
\end{tabular}

Peneliti melakukan tabulasi silang untuk mengetahui hubungan dukungan petugas kesehatan dengan perilaku wus dalam pemeriksaan IVA. 34 responden yang mendapatkan dukungan tinggi dari petugas kesehatan sebanyak $(64,7 \%)$ atau 22 reponden melakukan pemeriksaan. Sedangkan dari 10 responden yang mendapatkan dukungan rendah dari petugas kesehatan sebanyak $(80 \%)$ atau 8 orang tidak melakukan pemeriksaan.

\section{Pembahasan}

a. Dukungan Petugas Kesehatan

Hasil penelitian ini menunjukkan mayoritas wanita usia subur $(55,7 \%)$ atau 34 responden mendapatkan dukungan petugas kesehatan yang tinggi. Sedangkan sebanyak $(16,4 \%)$ atau 10 responden mendapat dukungan petugas kesehatan yang rendah.

Tingginya dukungan petugas kesehatan disebabkan oleh aktifnya petugas kesehatan dalam 
memberikan informasi mengenai pemeriksaan IVA maupun mengajak WUS yang berkunjung ke puskesmas untuk melakukan pemeriksaan. Petugas kesehatan yang dimaksud dalam penelitian ini adalah dokter, bidan dan perawat. Hasil analisis dari jawaban wanita usia subur tentang petugas kesehatan yang memberikan dukungan, mayoritas (80\%) wanita usia subur menyatakan dukungan diberikan oleh Bidan.

Banyaknya responden yang memilih bidan dikarenakan interaksi wanita usia subur dengan bidan lebih sering dibanding dengan petugas kesehatan yang lain. Dukungan yang diberikan bidan kepada wanita usia subur, antara lain dengan menanyakan keluhan-keluhan terkait tanda dan gejala kanker leher rahim, bidan memfasilitasi pemeriksaan, bidan memberikan konseling terkait IVA pada saat ibu melakukan pemasangan KB. Dukungan bidan terhadap pemeriksaan IVA akan mempengaruhi perilaku wanita dalam melakukan pemeriksaan karena dukungan merupakan faktor yang mempengaruhi tindakan kesehatan individu, kelompok, atau masyarakat (Nova, 2012).

Hasil penelitian tersebut sesuai dengan penelitian Luthfiana Dewi (2014) faktor-faktor yang berhubungan dengan perilaku WUS dalam deteksi dini kanker leher rahim metode IVA bahwa ada hubungan yang signifikan antara dukungan petugas kesehatan dengan perilaku pemeriksaan IVA dengan p value 0,004 < 0,05 (Dewi, 2014).

Keterampilan konseling, kemampuan berkomunikasi dengan baik dan dapat dengan mudah diterima oleh responden dapat mendukung pemeriksaan IVA. Keterampilan konseling yang baik dalam memberikan dukungan dibuktikan dengan hasil penelitian bahwa sebagian besar responden yaitu 90\% menyatakan petugas kesehatan menjelaskan pemeriksaan IVA dilakukan dibagian jalan lahir menggunakan cairan yang diolesi dengan kapas dan menggunakan peralatan yang aman. Selain itu, 88\% responden juga menyatakan bahwa petugas kesehatan menyarankan untuk melakukan pemeriksaan IVA sedini mungkin dan dengan rentang waktu 3-5 tahun.

Petugas kesehatan yang mempunyai keterampilan konseling yang baik akan lebih dipercaya oleh masyarakat. Kepercayaan ini akan menimbulkan percaya diri petugas kesehatan untuk mendukung keberhasilan pemeriksaan IVA, sehingga bidan mampu berkomunikasi dengan baik dan dapat dengan mudah diterima oleh responden. Selain itu petugas kesehatan yang terampil akan merasa memiliki kemampuan yang baik untuk memberikan dukungan. Hal ini yang akan memotivasi untuk meningkatkan dukungan terhadap pemeriksaan IVA (Maryam, 2012).
Ketrampilan (skill) merupakan salah satu faktor untuk mencapai kompetensi dalam memberikan dukungan. Ketrampilan juga mencakup ketrampilan sebagai konselor yaitu seorang mampu memberikan informasi dan penjelasan, termasuk mendengarkan, menanyakan keluhan, dan membantu klien dan keluarga dalam memahami berbagai masalah yang ingin mereka ketahui. Petugas kesehatan bertanggungjawab memberikan informasi terkini dan menyampaikan dalam bahasa sederhana dan cara yang jelas misal dengan pemberian contoh (Maryam, 2012).

Beberapa WUS yang mendapatkan dukungan sedang dan rendah dikarenakan kurangnya interaksi dengan petugas kesehatan. Pemberian dukungan terkait informasi dan ajakan untuk melakukan pemeriksaan IVA oleh petugas kesehatan dilakukan pada WUS yang melakukan kunjungan ke puskesmas atau berinteraksi langsung dengan petugas kesehatan, sehingga interkasi WUS yang kurang dengan petugas kesehatan akan menyebabkan informasi yang diterimanya berkurang.

Dukungan petugas kesehatan sangat penting dan diharapkan mampu mempengaruhi perilaku seseorang karena dukungan merupakan faktor yang mempengaruhi tindakan kesehatan individu, kelompok, atau masyarakat. Upaya agar masyarakat berperilaku atau mengadopsi perilaku kesehatan dengan cara persuasi, bujukan, himbauan, ajakan, memberi informasi, memberikan kesadaran, dan sebagainya melalui kegiatan yang disebut pendidikan atau promosi kesehatan oleh tenaga kesehatan (Nurhastuti, 2013).

\section{b. Perilaku Wanita Usia Subur dalam Pemeriksaan IVA}

Hasil penelitian ini menunjukkan mayoritas perilaku wanita usia subur (59\%) atau 36 responden telah melakukan pemeriksaan IVA. Sedangkan sebanyak (41\%) atau 25 responden tidak melakukan pemeriksaan IVA.

Banyaknya responden yang telah melakukan pemeriksaan dapat disebabkan oleh faktor usia. Dalam penelitian ini sebagian besar (59\%) responden berusia < 40 tahun. Usia seseorang mempengaruhi kematangan seseorang untuk menerima informasi dan pengalaman, sehingga menentukan seseorang untuk berperilaku sesuai dengan informasi dan pengalaman yang telah diterima. Semakin tua usia seseorang, kematangan dalam menerima informasi akan semakin baik, sehingga akan menimbulkan perilaku yang baik sesuai dengan infromasi yang diterimanya (Notoatmodjo, 2010). Hasil penelitian ini sesuai dengan penelitian yang dilakukan oleh Rohmawati 
tahun 2011 bahwa ibu yang melakukan pemeriksaan sebanyak $78,5 \%$ berusia diatas 35 tahun (Rohmawati, 2011).

Hal ini sesuai dengan anjuran Depkes RI (2010) bahwa deteksi dini Kanker Leher Rahim dianjurkan pada perempuan usia 30-50 tahun, karena lesi prakanker lebih mungkin terdeteksi yaitu 10-20 tahun lebih awal. Sejalan dengan teori Notoatmodjo (2010) menyatakan perilaku dipengaruhi oleh usia individu. Semakin cukup usia seseorang, akan lebih matang dalam berpikir sehingga lebih mudah memahami informasi untuk menambah pengetahuan. Hal ini sebagai akibat dari pengalaman dan kematangan jiwa (Notoatmodjo, 2010).

Selain usia, pendidikan juga dapat mempengaruhi perilaku seseorang. Pada penelitian ini mayoritas responden $(54,1 \%)$ atau 33 responden ada dalam kelompok pendidikan tinggi. Semakin tinggi tingkat pendidikan seseorang, semakin mudah menerima informasi sehingga semakin banyak menerima pengetahuan, dan jika tingkat pendidikan rendah, maka akan menghambat perkembangan perilaku seseorang terhadap penerimaan, informasi, nilai-nilai yang baru diperkenalkan (Maryam, 2012).

Hasil penelitian tersebut sejalan dengan Purba Evi M, dalam penelitiannya tahun 2011 bahwa yang memiliki pendidikan tinggi lebih banyak yang melakukan pemeriksaan untuk deteksi dini kanker leher rahim yaitu sebanyak 65,3\%. Penelitian yang dilakukan oleh Artiningsih (2011) juga menyatakan bahwa seseorang yang berpendidikan lebih tinggi akan lebih mudah menerima informasi dan pengetahuan dibandingkan dengan orang yang berpendidikan rendah (Artiningsih, 2011).

Pada penelitian ini juga diketahui alasan perilaku wanita usia subur tidak melakukan pemeriksaan IVA yakni malu dan takut, tidak tahu tentang pemeriksaan IVA, belum sempat melakukan pemeriksaan dan belum memiliki anak. Dari total 25 responden yang tidak melakukan pemeriksaan, sebagian besar (56\%) atau 14 responden menyatakan tidak mengetahui adanya pemeriksaan IVA. Sebanyak (40\%) atau 10 responden merasa malu dan takut melakukan pemeriksaan dan (4\%) atau 1 orang menyatakan belum sempat melakukan pemeriksaan. Banyaknya wanita usia subur yang masih malu dan takut untuk melakukan pemeriksaan serta beranggapan bahwa keadaan atau kondisi kesehatannya yang sehat menyebabkan wanita merasa tidak perlu melakukan pemeriksaan IVA.

Alasan yang dikemukakan responden sejalan dengan penelitian Emilia (2010). Perilaku WUS untuk melakukan deteksi dini kanker leher rahim juga dipengaruhi beberapa kendala sosial pada masyarakat yang menghambat deteksi dini, salah satunya berkaitan dengan konsep tabu melakukan pemeriksaan karena pemeriksaan tersebut dan kanker leher rahim menyerang pada bagian tertutup (Emilia, 2010).

c. Hubungan Dukungan Petugas Kesehatan dengan Perilaku WUS dalam Pemeriksaan IVA Hasil penelitian ini menunjukkan ada hubungan dukungan petugas kesehatan dengan perilaku wanita usia subur (WUS) dalam pemeriksaan IVA, dengan nilai signifikansi o,o21. Keeratan hubungan dalam penelitian ini didapatkan koefisien kontingensi o,335 yang berarti dukungan petugas kesehatan dengan perilaku WUS dalam pemeriksaan IVA dalam tingkatan rendah.

Berdasarkan analisis kuisioner dukungan petugas kesehatan terkait pemberian dukungan informasi, mayoritas responden (62\%) yang menyatakan ya terkait dukungan petugas kesehatan selanjutnya menunjukkan perilaku melakukan pemeriksaan IVA. Hal tersebut menunjukkan dukungan informasional dari petugas kesehatan berperan dalam perubahan perilaku responden. Peran petugas kesehatan selain memberikan pelayanan kesehatan kepada masyarakat juga sebagai edukator yang memberikan konseling, informasi dan edukasi terkait program atau pemeriksaan IVA dalam asuhan dan pelayanan kesehatan agar masyarakat mampu untuk memelihara dan meningkatkan derajat kesehatan mereka (Novita, 2012).

Menurut WHO apabila seseorang tersebut penting untuknya, maka apa yang dikatakan atau diperbuatnya cenderung untuk dicontoh. Orangorang yang dianggap penting ini sering disebut kelompok referensi (reference group). Petugas kesehatan merupakan salah satu dalam kelompok referensi, dan sebagai sumber informasi tentang kesehatan dalam hal ini tentang pemeriksaan IVA (Wahidin, 2015).

Penelitian yang dilakukan oleh Ismarwati (2011) mengenai pengaruh promosi kesehatan tentang kanker serviks didapatkan hasil bahwa promosi kesehatan dengan media audio visual dan metode diskusi interaktif dapat meningkatkan pengetahuan dan sikap tentang kanker serviks dan deteksi dini pada ibu-ibu anggota pengajian. Meningkatnya pengetahuan dan sikap tersebut akan mampu mendorong perubahan perilaku jika dilakukan dengan memberikan dukungan dalam bentuk lain seperti dukungan emosional dan instrumental (Ismarwat, 2011).

Oleh sebab itu tidak hanya diperlukan informasi tetapi motivasi yang besar untuk WUS agar mau mengikuti pemeriksaan IVA. (Nurus, 
2010). Hasil penelitian tersebut sejalan dengan teori perilaku yang menyatakan selain dukungan informasional, diperlukan juga bentuk dukungan lain seperti dukungan emosional. Dukungan emosional dapat diberikan dengan cara memotivasi atau memberikan dorongan berupa perhatian, kepedulian yang berarti bagi individu sehingga dapat merasakan ketenangan jiwa (Notoatmodjo, 2010).

Peneliti menganalisis beberapa sampel pernyataan kuisioner terkait pemberian dukungan emosional. 60\% dari 50 responden tersebut menunjukkan perilaku melakukan pemeriksaan. Hal tersebut menunjukkan masih diperlukannya peran petugas sebagai motivator untuk memberikan dukungan. Sejalan dengan hal tersebut, Twin, Shiu dan Holroyd menyatakan bahwa wanita yang diingatkan oleh petugas kesehatan untuk melakukan pemeriksaan kesehatan cenderung memiliki keinginan yang kuat untuk melakukan pemeriksaan tersebut. Upaya yang dapat dilakukan petugas kesehatan adalah dengan mendampingi, menyadarkan dan mendorong kelompok untuk mengetahui pentingnya upaya pencegahan dan deteksi dini penyakit, salah satunya kanker leher rahim melalui deteksi dini pemeriksaan IVA (Novita, 2012).

Wanita cenderung mendapatkan informasi yang buruk, memiliki pemahaman yang terbatas dan memiliki banyak pertanyaan yang tidak terjawab. Hal ini meningkatkan kecemasan dan mengurangi kemampuan wanita untuk membuat keputusan berdasarkan informasi. Sehingga diperlukan metode penyampaian informasi yang dapat menjangkau seluruh lapisan masyarakat, baik melalui media maupuan perpanjangan tangan tenaga kesehatan (Hendry et al, 2012).

Dukungan yang lebih dekat pada masyarakat khususnya WUS, dapat dilakukan dengan menawarkan melakukan pemeriksaan IVA saat WUS melakukan kunjungan ke fasilitas kesehatan, maupun menggerakkan WUS untuk melakukan pemeriksaan bersama melalui kader kesehatan yang lebih dekat dengan masyarakat. Wanita yang diingatkan oleh petugas kesehatan untuk melakukan pemeriksaan kesehatan cenderung memiliki keinginan yang kuat untuk melaksanakan pemeriksaan tersebut (Wati, 2015).

Dukungan instumental juga diperlukan dalam proses perubahan perilaku. Analisis pernyataan kuisioner terkait dukungan instrumental yang diberikan petugas kesehatan tentang adanya pemeriksaan IVA secara gratis menunjukkan 46 responden menyatakan ya dan $74 \%$ melakukan perilaku pemeriksaan IVA. Dukungan ini dapat berbentuk materi dan bersifat nyata yang dapat memberikan pertolongan langsung yang bertujuan untuk meringankan beban individu yang memiliki kebutuhan atau dapat mengurangi tingkat stress akibat masalah yang berhubungan dengan materi sehingga secara langsung dapat dipecahkan (Tilong, 2012).

Pentingnya dukungan petugas kesehatan terhadap perubahan perilaku kesehatan diperkuat dengan penelitian Yuliwati (2012) didapatkan hasil ada hubungan antara dukungan petugas kesehatan dengan perilaku periksa IVA. Wanita usia subur yang mendapatkan dukungan petugas kesehatan baik berpeluang 2 kali lebih besar daripada yang mendapat dukungan kurang (Yuliwati, 2012).

Keeratan hubungan dukungan petugas kesehatan dengan perilaku WUS dalam pemeriksaan IVA yang masih dalam tingkat rendah dapat disebabkan kurangnya interakasi beberapa responden dengan petugas kesehatan. Kurangnya peran kader sebagai pembantu tenaga kesehatan dalam menyampaikan informasi juga dapat menjadi faktor yang mempengaruhi perilaku. Peran kader sebagai pembantu tenaga kesehatan termasuk dalam dukungan sosial. Menurut Gottlieb dalam Nursalam (2007) terdapat pengaruh dukungan sosial terhadap perilaku kesehatan.

Mc Farland dalam penelitiannya menyatakan faktor lain yang dapat mempengaruhi perilaku peneriksaan IVA anatara lain kurangnya pengetahuan dan kesadaran tentang deteksi dini. Penelitian melaporkan, wanita tidak tahu pelayanan deteksi dini kanker serviks. Sikap dan keyakinan juga ikut mempengaruhi. Sebagian wanita beranggapan jika detksi dini tidak memiliki manfaat karena adanya pemikiran bahwa kanker serviks tidak dapat dicegah sehingga menganggap deteksi dini tidak penting. Hal lain yangterkait adalah faktor budaya dan keyakinan. Beberapa wanita menyatakan bahwa deteksi dini bertentangan dengan kebidayaan dan keyakinan yang mereka anut. Kebudayaan dan keyakinan mereka tidak mendorong untuk menunjukkan tubuh pada laki-laki lain selain suami (McFarland et al, 2016).

Penelitian lainnya menyatakan perlunya dukungan dari tokoh masyarakat. Dukungan yang diberikan dalam bentuk adanya pertemuan dengan masyarakat, dimana dalam pertemuan tersebut adanya pemberian informasi terkait deteksi dini kanker serviks. Hal ini meningkatkan kesadaran masyarakat sebelum adanya kunjungan. Meskipun sebelumnya telah ada edukasi melalui media elektronik namun tidak semua masyarakat pedesaan mampu mengakses informasi melalui sumber tersebut (Chigbu et al, 2012).

Cara dan proses penyampaian informasi juga dapat mempengaruhi perubahan prilaku kesehatan, 
Penyampaian informasi menggunakan media audio visual sehingga diharapkan kesadaran masyarakat dapat muncul atau meningkat. Oldach and Katz dalam penelitiannya juga menyatakan perlunya dukungan dari suami. Sebagian besar wanita yang hadir dalam pemutaran film terkait edukasi deteksi dini karena di dorong oleh suami mereka. Keterlibatan keluarga perlu dieksplorasi lebih jauh untuk meningkatkan kesadaran wanita untuk melakukan deteksi dini (Oldach and Katz, 2013).

\section{SIMPULAN DAN SARAN}

\section{Simpulan}

Ada hubungan antara dukungan petugas kesehatan dengan perilaku WUS dalam pemeriksaan IVA. Keeratan hubungan antara dukungan petugas kesehatan dengan perilaku WUS dalam pemeriksaan IVA berada dalam tingkat rendah. Hal tersebut dapat dsebabkan karena beberapa hal, salah satunya kurangnya interakasi beberapa responden dengan petugas kesehatan.

\section{Saran}

Menggunakan media dan cara penyampaian informasi dan motivasi yang beragam sehingga mampu menarik perhatian masyarakat. Meningkatkan interaksi dan konseling sehingga masyarakat dapat lebih mudah menerima informasi dan termotivasi untuk meningkatkan derajat kesehatannya.

\section{UCAPAN TERIMA KASIH}

Peneliti mengucapkan terima kasih kepada pembimbing yang telah banyak membantu dan mengarahkan dalam penelitian ini.

\section{DAFTAR RUJUKAN}

[1] Emilia, O. 2010. Bebas Ancaman Kanker Serviks. Yogyakarta: Media Pressindo.

[2] Maryam. 2012. Peran Bidan yang Kompeten Terhadap Suksesnya MDG's. Jakarta: Salemba Medika.

[3] Notoatmodjo, S. 2010. Pendidikan dan Perilaku Kesehatan, Jakarta: Rineka Cipta.

[4] Nova, M. 2014. Sosiologi dan Antropologi Kesehatan, Yogyakarta: Nuha Medica.

[5] Novita, N. 2012. Promosi Kesehatan Pelayanan Asuhan Kebidanan. Yogyakarta: Salemba.

[6] Tilong, A. D. 2012. Bebas dari Ancaman Kanker Serviks. Jakarta: Flash Book.

[7] Artiningsih, N. 2011. Hubungan antara Tingkat Pengetahuan dan Sikap Wanita Usia Subur dengan Pemeriksaan Inspeksi Visual Asam Asetat dalam Rangka deteksi Dini kanker Serviks. Program Pasca Sarjana Universitas Sebelas Maret. Surakarta.

[8] Chigbu, CO. Onyebuchi, AK. Ajah, LO. Onwudiwe, EN. 2013. Motivations and Prefrences of Rural Nigeria Woman Undergoing Cervical Cancer Screening via Visual Inspection with Acetic Acid. International Journal of Ginecology and Obstetrics 120 (2013) 262-265.

[9] Dewi, L. 2014. Faktor-Faktor yang Berhubungan dengan Perilaku WUS Dalam Deteksi Dini Kanker Leher Rahim
Metode IVA Di Wilayah Kerja Puskesmas Tanjung Hulu. Pontianak: FK UTP. Diakses pada tanggal o8 Januari 2016.

[10] Hendry, $\mathrm{M}$ et al. 2012. Are women ready for the new cervical screening protocol in england? A systematic review and qualitative synthesis of views about human papillomavirus testing. British Juornal of Cancer 107 (2012) 243-254.

[11] Ismarwati. 2011. Promosi Kesehatan dalam Meningkatkan Pengetahuan, Sikap dan Perilaku Deteksi Dini Kanker Servics pada Ibu-Ibu Anggota Pengajian As Sakinah di Kecamatan Banguntapan. Berita Kedokteran Masyarakat Volume 2.

[12] Krishnan, Seneeta. Madsen, Emily. Porterfield, Deborah. Varghese, Beena. 2013. O ncologist Advancing Cervical Cancer Prevention in India : Implementation. The Oncologist 2013;18;1285-1297.

[13] McFarland, Ditsapelo et al. 2016. Integrated Review of Barriers to Cervical Cancer Screening in Sub-Saharan Africa. Journal Nurshing Scholarship 48 (2016) 490-498.

[14] Nurhastuti, Y. 2013. Faktor-Faktor yang Berhubungan dengan Perilaku PUS dalam Deteksi Dini Kanker Serviks dengan Metode IVA di Wilayah Kerja Puskesmas Kebumen I Kabupaten Kebumen. Prodi S1 Keperawatan Stikes Muhammadiyah.

[15] Nurus. 2010. Faktor-Faktor Yang Berhubungan Dengan Motivasi Wanita Usia Subur Yang Melakukan Pemeriksaan IVA Dalam Upaya Deteksi Kanker Serviks. Diakses pada $\begin{array}{llll}\text { tanggal } 20 & \text { Desember } & 2015 & \text { dari }\end{array}$ http://lppm.stikesnu.com/wpcontent/uploads/2014/o2/b.nurus_.pdf.

[16] Oldach, BR. Katz, ML. 2014. Health Literacy and Cancer Screening: A Systematic Review. Patient Educ Couns. 2014 February ; 94(2): 149-157.

[17] Rohmawati, I. 2011. Faktor-Faktor yang Berhubungan dengan Wanita Usia Subur dalam Deteksi Dini Kanker Serviks dengan Metode IVA (Inspeksi Visual Asam Asetat) di Wilayah Kerja Puskesmas Ngawen I Kabupaten Gunung Kidul Tahun 2011. Jakarta: FKM UI.

[18] Wati, Dewi Sapta. 2015. Faktor-Faktor yang Berhubungan dengan Perilaku WUS Dalam Deteksi Dini Kanker Leher Rahim Metode IVA Di Desa Genuk Kecamatan Ungaran Barat. Semarang: Prodi DIV Kebidanan Stikes Ngudi Waluyo. Diakses pada tanggal o8 Januari 2016.

[19] Yuliwati. 2012. Faktor-Faktor yang Berhubungan dengan Perilaku WUS Dalam Deteksi Dini Kanker Leher Rahim Metode IVA Di Wilayah Puskesmas Prembun Kabupaten Kebumen. Skripsi. Jakarta: FKM UI. Diakses pada tanggal 20 Desember 2015.

[20]Abdi, Alfian P. 2019. Kemnekes: Kanker Payudara \& Serviks Paling Banyak di Indonesia. Diakses dari: https://tirto.id/dfSv.

[21] Depkes RI. 2010. Keputusan Menteri Kesehatan Republik Indonesia Nomor 796/Menkes/SK/VII/2010 Tentang Pedoman Teknis Pengendalian Kanker Payudara dan Kanker Leher Rahim. Jakarta.

[22] Putri, Gloria S. 2019. Meningkat, Kasus Kanker Serviks Baru Di Indonesia 32.469 Jiwa di 2018. Diakses dari: https://sains.kompas.com/read/2019/o2/20/125618223/ meningkat-kasus-kanker-serviks-baru-di-indonesia32469-jiwa-di-2018?page $=$ all.

[23] Riskesdas, 2013. Riset Kesehatan Dasar, Badan Penelitian dan Pengembangan Kesehatan. Jakarta: Kemenkes RI.

[24] Sartika, Resa E.A. 2018. WHO Serukan Tindakan Cepat Basmi Kanker Serviks. Diakses dari: https://sains.kompas.com/read/2019/02/04/203033023 /who-serukan-tindakan-cepat-basmi-kanker-serviks

[25] Wahidin, M. 2015. Buletin Jendela Data dan Informasi Kesehatan Deteksi Dini Kanker Leher Rahim dan Kanker Payudara di Indonesia. Jakarta: Kemenkes RI.

[26] World Health Organization. 2015. Cancer Country Profiles. [27] http://www.who.int/cancer/prevention/diagnosisscreening/cervicalcancer/en//. 
52 Midwifery Journal | Vol. 4, No. 2, Juli 2019, hal 46-52

\section{PROFIL PENULIS UTAMA}

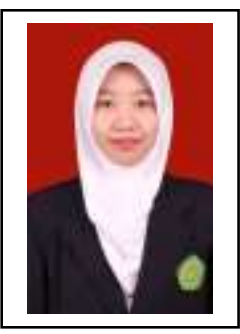

Shufia Aulia Citra, lulusan program magister S2

Kebidanan Universitas 'Aisyiyah Yogyakarta. 